\title{
Impact of Berberine on Some Epigenetic, Transcription Regulation and Inflammatory Biomarkers in a Mice Model of Epilepsy
}

\author{
Heba Bassiony Ghanem*1,2, Marwa Nagy Emam³, \\ Dareen Abdelaziz Mohammed Ali ${ }^{4}$, Rania Nagi Abd-Ellatif ${ }^{2}$
}

\begin{abstract}
Background: Epilepsy is one of the most widespread neurological disease worldwide. Status epilepticus (SE) is a life-threatening neurologic disorder. Neuroprotective approaches are increasingly to discover a promising therapy to manage epileptic disorders. This study aimed to assess the impact of berberine on some epigenetic, transcription regulation \& inflammatory biomarkers in a mice model of epilepsy.

Methods: This work was performed on; Group I: (control), Group II: berberine-treated control, Group III: epilepsy group, Group IV: berberine-treated epilepsy. Groups were subjected to assessment of Tumor growth factor-1 $\beta$ (TGF-1 $\beta$ ), hypoxia inducible factor- $1 \alpha$ (HIF-1 $\alpha$ ), brain derived neurotrophic factor (BDNF) levels, histone deacetylase (HDAC) activity \& neuronal restrictive silencing factor (NRSF) gene expression.

Results: Study showed significant increase in levels of HIF-1 $\alpha$, TGF-1 $\beta$, HDAC activity \& NRSF gene expression in epilepsy group \& decrease in these levels in berberine treated epilepsy group. Significant decrease in BDNF levels in epilepsy \& elevation in them in berberine treated epilepsy group.

Conclusions: Our study showed the anti-epileptic impact of berberine via its regulatory effect on some epigenetic, transcription factors \& inflammatory biomarkers in a mice model of epilepsy.
\end{abstract}

Keywords: Berberine, Epigenetics, Epilepsy, Transcription regulation \& inflammatory biomarkers.

\section{Introduction}

Among the most common neurological diseases is epilepsy. It has the manifestations of repeated seizures that triggered by odd neuronal electrical activity in the central nervous system (CNS) (1). Some patients with epilepsy, if untreated or not responding to medication, may undergo an attack of sustained seizure activity, status epilepticus (SE), which considered one of the most serious life-threatening disorder (2).

During development of regulating neurons, neurotrophic factors exert a vital role in the creation of synaptic connections with peripheral targets in the digestive, cardiovascular and several other organs. Numerous neurotrophic factors can regulate functions of nervous system, involving brain-derived neurotrophic factor (BDNF), ciliary neurotrophic factor and nerve growth factor. It has been established that BDNF, that control CNS functions, can be involved in several psychiatric and neurological disorders, such as epilepsy (3).

In addition, epilepsy has been accompanied by inflammation, neuronal apoptosis, and hippocampal neuronal loss. Numerous studies have reported that CNS inflammation can be considered as a cause and a consequence of epileptic seizures. One of the most powerful proinflammatory cytokine that has been recognized 
in the brain is tumor growth factor- $1 \beta$ (TGF- $1 \beta$ ) (4). Furthermore, seizures can be triggered by ischemia and CNS hypoxia, mostly in the hippocampus, and can motivate hypoxia inducible factor-1 $\alpha$ (HIF-1 $\alpha)$ increased expression (5).

Since additional factors are likely to promote the development of epilepsy as well, it has been proposed that epigenetic mechanisms such as DNA methylation may be involved in inducing seizures. According to this hypothesis, genetic epilepsy markers have been reported to be increased in histone modification markers, indicating the role of epigenetic control of gene transcription in epilepsy pathogenesis (6).

The transcriptional repressor of the neuronal restrictive silencing factor (NRSF) is known as one of the most potent neuronal plasticity mediators. Initially, NRSF expression was identified in non-neuronal tissues where it reduces the expression of neuron-specific genes, suggesting that NRSF response elements (NRSE / RE1) must be carried by many neuronal genes. Another important function for NRSF was identified by presenting that separation of NRSF from the chromatin of neuronal genes is required to transfer neuronal precursors to mature neurons. In addition, NRSF expression may be vital for normal neuronal function in mature neurons (7). In differentiated neurons, the expression of NRSF regulated genes contributes to many aspects of maturation, involving the development of excitatory synapses. It has indeed been shown that in rodent models, preventing the binding of the transcription factor NRSF to chromatin increases the development of epileptic seizures and inhibits memory disorders (8).

The best available anti-seizure drugs (ASDs), which are the chief treatment for seizures but the epileptogenesis mechanism cannot be alleviated. In addition, one-third of epileptic patients with ASDs do not demonstrate an adequate response, i.e. no reduction in seizure frequency and/or seizure intensity (9). Another challenge in the treatment of epilepsy is the side effects of ASDs, which are considered to be the primary reason for stopping of treatment in around one quarter of patients suffering from epilepsy. Consequently, the prerequisite for new, more efficient and safer ASDs is important (10). A natural compound derived from the Coptis chinensis traditional Chinese herb, Berberine (BBR), has been known for several years to have an efficient role on diarrhea treatment. Studies have shown that BBR has a critical therapeutic impact on heart disease, diabetes, hyperlipidemia, and inflammation as well. BBR has also been recognized as having a neuroprotective effect on multiple CNS disorders, such as Alzheimer's disease and epilepsy (11).

Therefore, herb-derived compounds like BBR may be an enticing alternative to the current ASDs. The search for effective anticonvulsive compounds may also help to discover novel anticonvulsant action mechanisms.

This work pointed to study the impact of Berberine (BBR) on some epigenetic \& transcription regulation \& inflammatory biomarkers in a mice model of epilepsy.

\section{Materials and Methods Chemicals}

Sigma-Aldrich Chemicals (St. Louis, MO) company was the source of purchase of Berberine hydrochloride, pilocarpine hydrochloride, scopolamine methylnitrate \& diazepam and all the other chemicals were used.

\section{Animals}

This study has been carried out on 80 adult male albino mice with the average weight (25-30 g), obtained from Tanta University Animal House. Animals were held in wire mesh cages at room temperature, and they allowed free feeding of standard mice diet and water ad libitum under regulated environments (light/dark cycle, 25-28 $\left.{ }^{\circ} \mathrm{C}\right)$. the local ethical committee of Tanta University, Faculty of Medicine approved the study proposal. The experiment was carried out in compliance with the Guide for the care and Use of Laboratory Animals of the National Institutes of Health (NIH publication No 85-23, updated in 1996). 


\section{Experimental Design}

The mice were categorized to four groups (20 mice for each one).

\section{Group I (control group)}

were injected with $0.9 \%$ saline i.p once daily for one week before induction of epilepsy till the end of the experiment.

Group II (berberine-treated control group) were injected with berberine hydrochloride $(20 \mathrm{mg} / \mathrm{kg}$, i.p.) once daily for one week before induction of epilepsy and until the end of the experiment. Berberine hydrochloride was dissolved in $0.9 \%$ saline (12).

\section{Group III (epilepsy group)}

pilocarpine hydrochloride (340 mg / kg i.p.) was injected into mice once. In order to minimize peripheral cholinergic symptoms, scopolamine methylnitrate (1 mg / kg s.c.) was administered 30 minutes prior to pilocarpine hydrochloride injection. In 0.9 percent of saline, pilocarpine hydrochloride and scopolamine methylnitrate were dissolved (13).

\section{Group IV (berberine-treated epilepsy group)}

was injected with berberine hydrochloride (20 $\mathrm{mg} / \mathrm{kg}$, i.p.) once daily for one week prior to epilepsy induction and until the end of the experiment. Pilocarpine hydrochloride $(340 \mathrm{mg}$ $/ \mathrm{kg}$ i.p.) was also injected once into the mice. To reduce the peripheral cholinergic symptoms, scopolamine methylnitrate $(1 \mathrm{mg} / \mathrm{kg}$ s.c.) was administered 30 minutes before pilocarpine hydrochloride injection $(12,13)$.

Following pilocarpine hydrochloride injection, mice were meticulously observed for 120 minutes to notice any behaviors indicative of seizure activity. Mice with continuous seizure activity for 30 minutes (Status Epilepticus SE) have been identified as an effective response to pilocarpine hydrochloride.

Mice with continuous seizure activity for 30 minutes (Status Epilepticus SE) have been identified as an effective response to pilocarpine hydrochloride. For 120 minutes after pilocarpine hydrochloride injection, mice were continuously observed to note any behaviors suggestive of seizure disorder. Pilocarpine hydrochloride injection sequentially caused the following behavioral changes: facial automatism, akinesia, motions of the masticatory jaw, limbic seizures consisting of forelimb clonus with rearing, falling, and salivating. This form of behavior gradually built up into motor limbic seizures that evolved into SE repeatedly and rapidly. According to the Racine scale, epileptic behavior was graded: This was divided into 5 stages: 1 . Facial and mouth movements. 2. Nodding in the head. 3. Clonus Forelimb. 4. Rearing. 5. Rearing and falling.

A total motor seizure with loss of postural function was referred to as a Class 5 motor seizure. The percentage of convulsing animals and the percentage of surviving animals was estimated. Seizures were terminated by intraperitoneal injection of $10 \mathrm{mg} / \mathrm{kg}$ diazepam when mice had practiced SE for 1 hour. Free water-soaked food was given to all SE animals before they could eat regular dry-food pellets. Mice were sacrificed 24 hours after SE (14).

\section{Tissue Sampling}

All the animals under isoflurane anesthesia were killed by decapitation at the end of the experiment. The brain was excised, washed with ice-cold saline, dried and weighed on filter paper. The whole brain was split into three pieces. The first one was fixed in a $10 \%$ formal saline solution and preserved for histological analysis at room temperature for 24 hours. The second one was homogenized into a saline buffer of $50 \mathrm{mM}$ phosphate, $\mathrm{pH}$ 7.4. Using a cold centrifuge, the tissue homogenate was centrifuged at $1,000 \mathrm{rpm}$ for $10 \mathrm{~min}$ at $0{ }^{\circ} \mathrm{C}$. The supernatant was collected

and kept at $-20{ }^{\circ} \mathrm{C}$ until it was used in various biochemical tests and total protein content assay (15), though the third one was frozen at $-80^{\circ} \mathrm{C}$ until performance of Polymerase chain reaction (PCR).

\section{Brain tissue homogenate total proteins concentration assay}

According to the Bradford method, total protein concentration in brain tissue homogenate samples was calculated (Catalog 
number 500-0006; Bio-Rad protein assay) (15).

\section{Histone deacetylase (HDAC) activity assay}

According to the manufacturer's instructions, the assay was carried out using a colorimetric HDAC activity assay kit (BioVision Research Products, Mountain View, CA, USA). For the quantification of the overall HDAC, brain tissue homogenate samples were used. $10 \mu \mathrm{L}$ of $10 \times$ HDAC assay buffer and $5 \mu \mathrm{L}$ of colorimetric substrate were applied to the final volume of 85 $\mu \mathrm{L}$ of deionized water and stored for $1 \mathrm{~h}$ at 37 ${ }^{\circ} \mathrm{C}$. The samples were added to the 96-well plates. Consequently, to stop the reaction, $10 \mu \mathrm{L}$ of lysine developer was applied and kept for 30 min at $37{ }^{\circ} \mathrm{C}$. The absorbance was measured at $400 \mathrm{~nm}$ by the ELISA plate reader. Relative optical density (OD) values per microgram of protein were expressed as HDAC activity (16).

\section{Assessment of brain tumor growth factor-1及 (TGF-1ß) level}

Using ELISA assay kit (Cat \# ab119557; Abcam, Cambridge, USA) with the guide of manufacturer's guidelines.

\section{Assessment of brain hypoxia inducible factor-} 1a $(\mathrm{HIF}-1 \alpha)$ Level

Using ELISA kit (Biovision - Milpitas Blvd., Milpitas, USA), It was estimated following the manufacturer's instructions. Catalog number E4760-100.

\section{Assessment of the level of brain brain-derived neurotrophic factor (BDNF)}

It was assessed by ELISA kit (LifeSpan BioSciences), Catalog number LS-F2404, regarding the manufacturer's guidelines.

\section{Quantitative Real-Time PCR assessment of neuronal restrictive silencing factor (NRSF) gene expression}

According to the manufacturer's procedure, total RNA was isolated from brain tissue using the Gene JET RNA Purification Kit (Thermo Fisher Scientific, Waltham, catalog number K0731). Total RNA (5 $\mu \mathrm{g})$ as previously using by RevertAid $\mathrm{H}$ Minus Reverse Transcriptase (Thermo Scientific, catalog number EP0451) was reverse transcribed to yield cDNA. The cDNA was used as a template by using Step OnePlus real-time PCR system (Applied Biosystem) to identify the relative expression of the NRSF gene. The primers were made by Primer 5.0 software (17). The sequences were as following: NRSF, Forward primer 5'CACCTGCGAGCTGGCGAGAAC3'

Reverse primer 5'CACATTTTAAATGGCTTCTCTCACCTG $3^{\prime}$. The housekeeping gene GAPDH was used as a reference to determine target gene expression fold change with primer sequences; Forward primer:

5'CAACTCCCTCAAGATTGTCAGCAA3'.

Reverse primer: 5'GGCATGGACTGT GGTCATGA3')

By adding $12.5 \mu \mathrm{L}$ of $2 \times$ Maxima SYBR Green /ROX qPCR Master Mix (Thermo Scientific, catalog number K0221), $1 \mu \mathrm{L}$ reverse primer, 1 $\mu \mathrm{L}$ forward primer, $2 \mu \mathrm{L}$ of cDNA template, and $8.5 \mu \mathrm{L}$ of nuclease free water, a $25-\mu \mathrm{L}$ PCR mixture was generated. Initial denaturation for 10 min at $95^{\circ} \mathrm{C}, 40$ cycles of DNA denaturation amplification for 15 seconds at $95^{\circ} \mathrm{C}$, annealing for 30 seconds at $60{ }^{\circ} \mathrm{C}$ and extension for 30 seconds at $71{ }^{\circ} \mathrm{C}$ were adjusted for the thermal cycling conditions.

The temperature for the melting curve study was increased from 63 to $95{ }^{\circ} \mathrm{C}$ at the end of the last cycle. The comparative cycle threshold $2^{-}$ $\Delta \Delta \mathrm{Ct}$ approach was used for the relative levels of gene expression and normalized to housekeeping gene expression (18).

\section{Histopathological study}

In order to obtain 5 - $\mu \mathrm{m}$ paraffin parts stained with hematoxylin and eosin (H\&E) for histopathological evaluation by light microscopy, the first part of brain tissue was fixed in $10 \%$ formol saline solution for 24 hours at room temperature and then handled.

\section{Statistical Analysis}

Using SPSS software (version 23), the analysis was performed. The results were expressed as mean \pm standard deviation. The intergroup variation was calculated by the one-way ANOVA followed by the multiple comparison 
test of post hoc Tukey. When $p \leq 0.05$, the significance was considered.

\section{Results}

\section{Seizure status analysis}

As shown in Table (1): no seizure activity was observed in both group I \& group II, however, there were 18 animals were experiencing seizure activity in group III and 16 animals in group IV.

Table 1. Numbers and rates of epilepticus in each group.

\begin{tabular}{ccc}
\hline Group & Number & Rate \% \\
\hline Group I $(\mathrm{n}=20)$ & 0 & $0 \%$ \\
Group II $(\mathrm{n}=20)$ & 0 & $0 \%$ \\
Group III $(\mathrm{n}=20)$ & 18 & $90 \%$ \\
Group IV $(\mathrm{n}=20)$ & 16 & $80 \%$ \\
\hline
\end{tabular}

Group I: control group, Group II: berberine-treated control group, Group III: Epilepsy group \& Group IV: berberine-treated epilepsy group. Group I: control group, Group II: berberine-treated control group,

\section{Effect of berberine on brain tumor growth

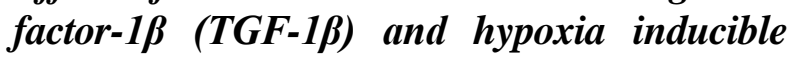 factor-1 $\alpha$ (HIF-1 $\alpha)$}

(Table 3) showed that there was significant increase in brain TGF- $1 \beta$ and brain HIF- $1 \alpha$ in epilepsy group (group III) compared to the

\section{Survival status analysis}

In contrast to $0 \%$ death rate in control group (group I) and berberine treated control group (group II), five rats died in epilepsy group (group III) with death rate $(25 \%)$ compared to $10 \%$ death rate (two rats) in berberine treated epilepsy group (group IV). Dead animals were excluded from our study and 15 mice were used in each group for accurate statistical analysis (Table 2).

Table 2. Numbers and rates of deaths in each group.

\begin{tabular}{ccc}
\hline Group & Number & Rate \% \\
\hline Group I $(n=20)$ & 0 & $0 \%$ \\
Group II $(\mathrm{n}=20)$ & 0 & $0 \%$ \\
Group III $(\mathrm{n}=20)$ & 5 & $25 \%$ \\
Group IV $(\mathrm{n}=20)$ & 2 & $10 \%$ \\
\hline
\end{tabular}

Group III: Epilepsy group \& Group IV: berberinetreated epilepsy group. *Statistics were done on 15 mice in each group to unify the numbers in each group.

control (group I) \& berberine treated control (group II). However, berberine treated epilepsy group (group IV) displayed significant decrease in brain TGF-1 $\beta$ and HIF-1 $\alpha$ compared to epilepsy group (group III).

Table 3. Effect of berberine on different parameters in the studied groups.

\begin{tabular}{|c|c|c|c|c|c|c|}
\hline Parameter/Groups & $\begin{array}{c}\text { Group I } \\
(\mathbf{n}=15)\end{array}$ & $\begin{array}{c}\text { Group II } \\
(\mathbf{n}=\mathbf{1 5})\end{array}$ & $\begin{array}{c}\text { Group III } \\
(n=15)\end{array}$ & $\begin{array}{c}\text { Group IV } \\
(\mathbf{n}=15)\end{array}$ & F value & p-value \\
\hline $\begin{array}{c}\text { TGF-1及 } \\
\text { (pg/mg tissue protein) }\end{array}$ & $80.96 \pm 6.2$ & $79.74 \pm 8.1$ & $204.01 \pm 11.2^{\mathrm{a}, \mathrm{b}}$ & $96.7 \pm 8.6^{\mathrm{a}, \mathrm{b}, \mathrm{c}}$ & 705 & $<0.001^{*}$ \\
\hline 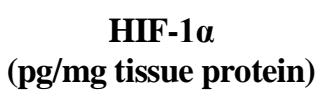 & $524.8 \pm 24.9$ & $515.3 \pm 25.3$ & $924.1 \pm 44.9^{\mathrm{a}, \mathrm{b}}$ & $712.5 \pm 18.02^{\mathrm{a}, \mathrm{b}, \mathrm{c}}$ & 618.8 & $<0.001 *$ \\
\hline $\begin{array}{c}\text { BDNF } \\
\text { (pg/mg tissue protein) }\end{array}$ & $102.5 \pm 4.6$ & $105.1 \pm 4.7$ & $54.4 \pm 5.8^{\mathrm{a}, \mathrm{b}}$ & $83.8 \pm 3.4^{\mathrm{a}, \mathrm{b}, \mathrm{c}}$ & 373.7 & $<0.001^{*}$ \\
\hline $\begin{array}{c}\text { HDAC activity } \\
\text { (nmol/mg protein) }\end{array}$ & $0.72 \pm 0.12$ & $0.8 \pm 0.11$ & $3.09 \pm 0.25$ a,b & $2.62 \pm 0.22^{a, b, c}$ & 653.6 & $<0.001 *$ \\
\hline
\end{tabular}

Group I: control group, Group II: berberine-treated control group, Group III: Epilepsy group \& Group IV: berberine-treated epilepsy group.

$*$ Values are expressed as mean \pm SD. Number of rats in each group $(n=15)$. $P$ was considered significant at $<0.05$. a Significance vs. group I, b Significance vs. group II \& c Significance vs. group III using One way ANOVA followed by Tukey’s post hoc test for multiple comparison. 
Table 4. Correlation between different studied parameters among the different studied groups.

\begin{tabular}{|c|c|c|c|c|c|c|c|}
\hline \multicolumn{2}{|c|}{$\begin{array}{c}\text { TGF-1及 } \\
\text { (pg/mg tissue protein) }\end{array}$} & \multicolumn{2}{|c|}{$\begin{array}{c}\text { HIF-1 } \alpha \\
\text { (pg/mg tissue protein) }\end{array}$} & \multicolumn{2}{|c|}{$\begin{array}{c}\text { BDNF } \\
\text { (pg/mg tissue protein) }\end{array}$} & \multicolumn{2}{|c|}{$\begin{array}{l}\text { HDAC activity } \\
\text { (nmol/mg protein) }\end{array}$} \\
\hline $\mathrm{r}$ & $\mathrm{p}$ & $\mathrm{r}$ & $\mathrm{p}$ & $r$ & $\mathrm{p}$ & $\mathrm{r}$ & $\mathrm{p}$ \\
\hline - & - & 0.905 & $<0.001^{*}$ & -0.918 & $<0.001^{*}$ & 0.725 & $<0.001^{*}$ \\
\hline 0.905 & $<0.001 *$ & - & - & -0.951 & $<0.001^{*}$ & 0.896 & $<0.001^{*}$ \\
\hline-0.918 & $<0.001 *$ & -0.951 & $<0.001 *$ & - & - & -0.880 & $0.001 *$ \\
\hline 0.725 & $<0.001 *$ & 0.896 & $<0.001 *$ & -0.880 & $0.001 *$ & - & - \\
\hline
\end{tabular}

Berberine effect on brain derived neurotrophic factor (BDNF)

(Table 3) showed that there was significant decrease in BDNF in epilepsy group (group III) compared to control group (group I) and berberine treated control group (II). However, berberine treated epilepsy group (group IV) showed significant increase in BDNF in comparison to epilepsy group (group III).

\section{Effect of berberine on histone deacetylase activity (HDAC)}

HADC activity showed significant increase in epilepsy group (group III) compared to control (group I) and berberine treated control (group
II). While in group IV, it was decreased significantly in comparison with group III (Table 3).

Effect of berberine on quantitative Real-Time PCR Analysis of neuronal restrictive silencing factor (NRSF) gene expression

Figure 1 shows that there was significant increase in NRSF gene expression in epilepsy group (group III) when compared with control group (group I) and berberine treated control group (group II). On the other hand, NRSF gene expression was decreased significantly in berberine treated epilepsy (group IV) as compared to (group III).

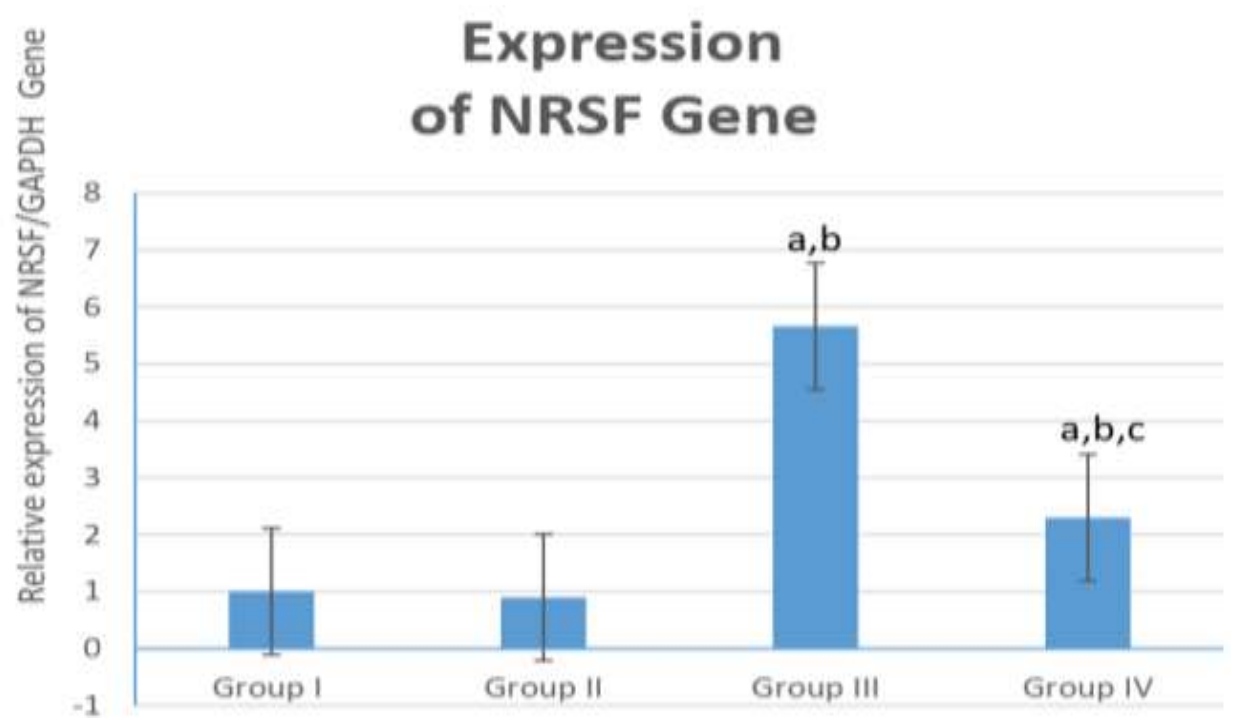

Fig. 1. The expression of NRSF gene in groups by Real-time PCR. Means within columns with different superscript letters are significantly different at $\mathrm{p}<0.05$, a: significance vs group I (control group), b: significance vs. group II (berberine treated control group), c: significance vs. group III (epilepsy group). 


\section{Bassiony Ghanem H et al}

\section{Histopathology}

Brain sections showed a normal histological structure in both control and berberine-treated control groups (Figs. 2A and 2B), whereas the epilepsy group showed dead neurons characterized by shrunken perikaryon, with karyorrhectic (arrow) and pyknotic
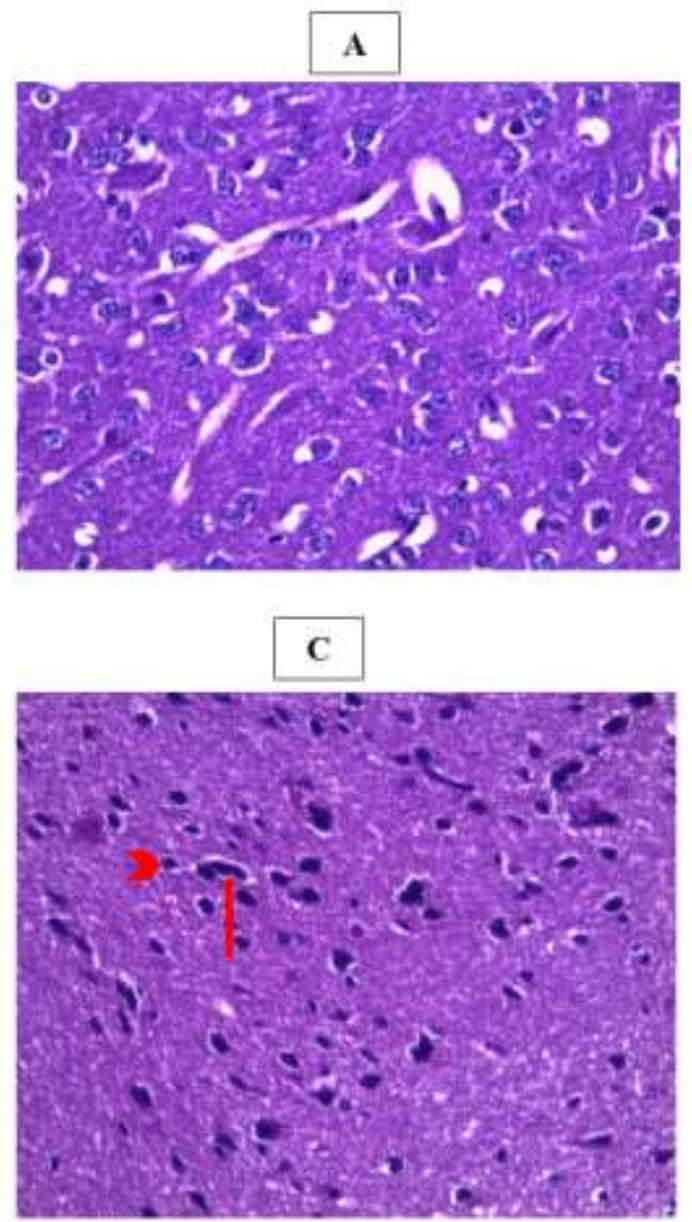

(arrowhead) nuclei \& disappearance of Nissl granules (Fig. 2C). On the other hand, berberinetreated epilepsy group showed that neurons have improved nuclear details with less pyknosis, denoting its ameliorating effect (Fig. 2D).
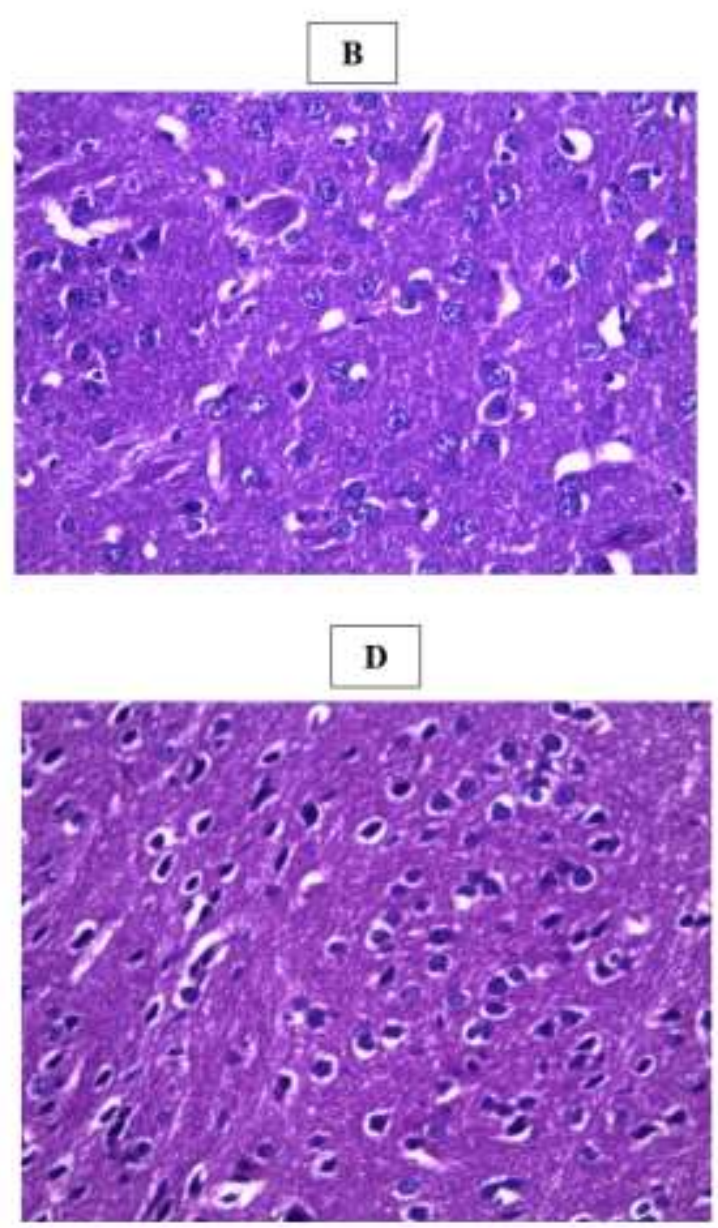

Fig. 2: The effects of treatments with berberine on brain tissues (H \& E 400X). A: Control group shows normal neurons, B: Berberine-treated control group shows dead neurons characterized by shrunken perikaryon with karyorrhectic (arrow) and pyknotic (arrowhead) nuclei and disappearance of Nissl granules. D: Berberine-treated epilepsy group showed that neurons have improved nuclear details with less pyknosis.

\section{Discussion}

One of the most common neurological diseases worldwide is epilepsy. Status epilepticus (SE) is a life-threatening neurological condition that induces epileptogenesis to convert healthy brain to an epileptic form. Spontaneous recurrent seizures that are difficult to treat usually follow SE. In order to prevent and cope with epileptic disorders, neuroprotective approaches are increasingly aimed at seeking a promising management. We studied in this study whether berberine (BBR) may ameliorate pilocarpineinduced SE and its epileptogenic disorder (19).

As a group of cytokines involved in intercellular communication, the tumor growth factor- $\beta$ (TGF- $\beta)$ protein family can be considered to regulate cellular processes, including cell growth, differentiation, inflammation and apoptosis $(20,21)$. The 
present study showed significant increase in TGF-1 $\beta$ levels in epilepsy group in comparison with other groups. Moreover, the levels of TGF$1 \beta$ were significantly decreased in berberine treated epilepsy group in comparison with epilepsy group. These findings coincided with (20) who established that the stimulation of brain TGF- $\beta$ signaling brings quick transcriptional programming, which contains inflammatory reactions, astrocytic transformation and late inhibition of gamma-amino-butyric acid (GABA)-related genes. The transformation of astrocytes and the associated inhibition of the potassium channel of the inward rectifier, gap junction proteins (connexins 30 and 43) and glutamate transporters caused the neuronal stimulation to increase extracellular potassium and glutamate, further enhancing the excitability of the network. TGF- $\beta$ signalling has since been involved in epileptogenesis (20).

Additionally, researchers reported that BBR decreased the amount of TGF- $1 \beta$ as it improved the antioxidant status by stimulating the nuclear factor E2-related factor2 (Nrf2) redox sensing transcription factor (22). Moreover, berberine effectively repressed the development of proinflammatory and pro-fibrotic mediators such as inducible nitric oxide synthase (iNOS), TGF-1 $\beta$ and TNF-alpha (22).

From another point of view, seizures can cause ischemia and brain hypoxia, particularly in the hippocampus, and can encourage increased expression of hypoxia inducible factor- $1 \alpha$ (HIF$1 \alpha)$ (5). The current study showed significant increase in HIF-1 $\alpha$ levels in epilepsy group in comparison with other groups and HIF-1 $\alpha$ levels were decreased significantly in berberine treated epilepsy group in comparison with epilepsy group. These results are in agreement with that showed by (5) who stated that HIF-1 $\alpha$ stimulates a series of consequent target genes for example, multidrug resistance gene 1 (MDR1), glucose transporter, vascular endothelial growth factor (VEGF) and erythropoietin (EPO). Furthermore, HIF-1 $\alpha$ regulates pro-inflammatory cytokines and modulates hippocampal apoptosis after SE (5). Also, it has been suggested that regulation of refractory epilepsy progression was dependent on modulating of HIF- $1 \alpha$ expression. HIF- $1 \alpha$
mRNA and protein expression were both enhanced in the temporal cortex of epileptic patients. We have therefore verified that HIF-1 $1 \alpha$ is a direct goal for antiepileptic drugs (23). In addition, it was approved that HIF- $1 \alpha$ stimulates microglia and astrocytes to initiate an inflammatory response, neutrophil migration and subsequent brain damage in the hypoxiaischemia model. It was established that overexpression of HIF- $1 \alpha$ aggravates inflammation and hippocampal apoptosis in the epilepsy model of animals (24). In addition, BBR functions as an HIF-1 $\alpha$ inhibitor that could decrease the expression of HIF- $1 \alpha$ in conditions of normoxia and hypoxia. The effect of BBR on HIF-1 $\alpha$ may account for its selective toxicity in diseased cells due to the unlike expression of HIF- $1 \alpha$ in diseased and normal cells. The inhibitory effect of BBR on HIF- $1 \alpha$ expression has been reported in many inflammatory disorders, such as cancers (25).

Pilocarpine-produced chronic seizures or status epilepticus (SE) activate various changes in gene expression that are assumed to lead to the progress of epilepsy. The seizure-induced variations in gene expression machinery are unclear, but may involve regulation of transcription or mRNA stability (26).

The present work exhibited significant increase in NRSF gene expression \& HDAC activity in epilepsy group in comparison with other groups and there was significant decrease in NRSF gene expression \& HDAC activity in berberine treated epilepsy group in comparison with epilepsy group. Also, the current study showed significant decrease in BDNF levels in epilepsy group in comparison with other groups and BDNF levels were increased significantly in berberine treated epilepsy group in comparison with epilepsy group. These findings are in accordance with (26) who recognized that the BDNF growth factor, which has been suggested to lead to seizure-induced pathological processes in the hippocampus, is among the numerous genes with expression alterations after seizures. The BDNF promoter has an inverted repressor element-1 (RE1) silencer element repeat that downregulates transcription in cortical glia and C6 glioma cells by binding to the RE1 repressor 
protein identified as repressor element silencing transcription factor (REST) or neuron-restrictive silencer factor (NRSF), which, in the promoter downregulates transcription in cortical glia by recruiting HDAC to the promoter. A condensed chromatin structure induced by histone deacetylation that protects promoters from transcription factors, thereby inducing transcriptional repression. Histone deacetylase inhibitors have been shown to increase the activity of the glia promoter (26).

Since NRSF is rapidly induced after seizures in the hippocampus, it has been established that seizure-induced BDNF mRNA downregulation is triggered by histone deacetylase \& NRSF transcription factor recruitment to the BDNF gene. Histones associated with BDNF promoters have been found to be rapidly deacetylated following seizures, and an HDAC inhibitor prevents both BDNF-associated histone deacetylation and BDNF mRNA downregulation following seizures (27).

Furthermore, (28) found that NRSF transcripts after seizures are rapidly triggered in the hippocampus. To repress neuronal gene expression, NRSF may bind to repressor proteins such as HDACs and/or methyl-DNA binding proteins (28). Additionally, a previous study found that serum BDNF levels in adult epilepsy patients were substantially reduced. The decreased serum level of BDNF has been substantially associated with bilateral tonicclonic seizures patients as a focal point. Therefore, it has been proposed that adult patients with more serious focal motor seizures may have reduced serum BDNF levels. Decreased serum levels of BDNF is in accordance with hypothesis that a deficiency in these neurotrophic factors may lead to the functional and structural changes in the brain

\section{References}

1. Gawel K, Kukula-Koch W, Nieoczym D, Stepnik K, Ent Wvd, Banono NS, et al. The Influence of Palmatine Isolated from Berberis sibirica Radix on Pentylenetetrazole-Induced Seizures in Zebrafish. Cells. 2020;9(5):1233.

2. Lenz M, Shimon MB, Deller T, Vlachos A, Maggio N. Pilocarpine-induced status epilepticus underlying the neurodegenerative process associated with chronic and severe epilepsy (3).

As well, researchers established for the first time that HDACs are downregulated by BBR (29). Elevated binding affinity against the HDAC family (4A69, 3MAX, 4BKX, and 2VQM) was shown by BBR ligands. They fit into the active site region precisely, and more hydrogen bond interactions were formed by the ligands. They anticipated that BBR could hinder HDAC, protein synthesis and AKT/mammalian targets of rapamycin pathways, that were wellcorrelated with our findings, exhibiting a high binding affinity of BBR with the HDAC family, suggesting the potential role of BBR in epigenetic modulation. By downregulation of HDAC enzymes, BBR has the capacity to implement epigenetic modifications (29).

It was investigated if berberine could reduce the depressive-like behavior caused by repeated injections of corticosterone and the possible mechanisms were investigated (30). Injection of exogenous corticosterone resulted in depressivelike actions in mice, along with reduced hippocampal levels of BDNF mRNA and protein They discovered that BBR treatment prevented decreased levels of BDNF mRNA and protein. These results demonstrated the successful impact of BBR mediating the BDNF up-regulation in hippocampus (30).

The present work emphasizes the antiepileptic impact of berberine via its regulatory effect on some epigenetic, transcription factors $\&$ inflammatory biomarkers in a mice model of epilepsy providing a promising treatment for the prevention and control of epileptic disorders.

\section{Acknowledgements}

All my colleagues who contributed and encouraged me to do this study.

is associated with changes in the actin-modulating protein synaptopodin and alterations in long-term potentiation in the mouse hippocampus. Neural Plast. 2017;2017:2652560.

3. Chen S-F, Jou S-B, Chen N-C, Chuang H-Y, Huang C-R, Tsai M-H, et al. Serum Levels of Brain-Derived Neurotrophic Factor and Insulin- 
Like Growth Factor 1 Are Associated with Autonomic Dysfunction and Impaired Cerebral Autoregulation in Patients with Epilepsy. Front Neurol. 2018;9:969.

4. Rad MM, Rad NM, Mirdamadi Y. Expression of TGF- $\beta 3$ in isolated fibroblasts from foreskin. Reports of biochemistry \& molecular biology. 2015;3(2):76-81.

5. Wu L, Li Y, Yang F, Wu B, Yu M, Tu M, et al. Silibinin inhibits inflammation and apoptosis in a rat model of temporal lobe epilepsy. Int $\mathbf{J}$ Clin Exp Med. 2018;11(3):1891-1899.

6. Caramaschi D, Hatcher C, Mulder RH, Felix JF, Cecil CA, Relton CL, et al. Epigenomewide association study of seizures in childhood and adolescence. Clinical epigenetics. 2020;12(1):1-13.

7. Singh-Taylor A, Molet J, Jiang S, Korosi A, Bolton JL, Noam Y, et al. NRSF-dependent epigenetic mechanisms contribute to programming of stress-sensitive neurons by neonatal experience, promoting resilience. Mol Psychiatry. 2018;23(3):648-657.

8. Patterson KP, Barry JM, Curran MM, SinghTaylor A, Brennan G, Rismanchi N, et al. Enduring memory impairments provoked by developmental febrile seizures are mediated by functional and structural effects of neuronal restrictive silencing factor. $\mathrm{J}$ Neurosci. 2017;37(14):3799-3812.

9. Engel Jr J. Approaches to refractory epilepsy. Ann Indian Acad Neurol. 2014;17(Suppl 1):S12-7.

10. Perucca P, Gilliam FG. Adverse effects of antiepileptic drugs. Lancet Neurol. 2012;11(9):792-802.

11. Zheng Y-M, Chen B, Jiang J-D, Zhang J-P. Syntaxin 1B mediates berberine's roles in epilepsy-like behavior in a pentylenetetrazoleinduced seizure zebrafish model. Front Mol Neurosci. 2018;11:378.

12. Bhutada P, Mundhada Y, Bansod K, Dixit P, Umathe S, Mundhada D. Anticonvulsant activity of berberine, an isoquinoline alkaloid in mice. Epilepsy Behav. 2010;18(3):207-10.

13. Cavalheiro E, Santos N, Priel M. The pilocarpine model of epilepsy in mice. Epilepsia. 1996;37(10):1015-9.
14. Racine RJ. Modification of seizure activity by electrical stimulation: II. Motor seizure. Electroencephalogr Clin Neurophysiol. 1972;32(3):281-94.

15. Bradford MM. A rapid and sensitive method for the quantitation of microgram quantities of protein utilizing the principle of protein-dye binding. Anal Biochem. 1976;72:248-54.

16. Kalaiarasi A, Anusha C, Sankar R, Rajasekaran S, John Marshal J, Muthusamy K, et al. Plant isoquinoline alkaloid berberine exhibits chromatin remodeling by modulation of histone deacetylase to induce growth arrest and apoptosis in the A549 cell line. J Agric Food Chem. 2016;64(50):9542-9550.

17. Cai L, Bian M, Liu M, Sheng Z, Suo H, Wang $Z$, et al. Ethanol-induced neurodegeneration in NRSF/REST neuronal conditional knockout mice. Neuroscience. 2011;181:196-205.

18. Livak KJ, Schmittgen TD. Analysis of relative gene expression data using real-time quantitative PCR and the $2-\Delta \Delta C T$ method. methods. 2001;25(4):402-8.

19. Sedaghat R, Taab Y, Kiasalari Z, AfshinMajd S, Baluchnejadmojarad T, Roghani M. Berberine ameliorates intrahippocampal kainateinduced status epilepticus and consequent epileptogenic process in the rat: Underlying mechanisms. Biomed Pharmacother. 2017;87:200-208.

20. Bar-Klein G, Cacheaux LP, Kamintsky L, Prager O, Weissberg I, Schoknecht K, et al. Losartan prevents acquired epilepsy via TGF- $\beta$ signaling suppression. Ann Neurol. 2014;75(6):864-75.

21. Khakzad MR, Salari F, Javanbakht M, Hojati M, Varasteh A, Sankian M, et al. Transforming growth factor beta $1869 \mathrm{~T} / \mathrm{C}$ and 915G/C polymorphisms and risk of autism spectrum disorders. Rep Biochem Mol Biol. 2015;3(2):82-88.

22. Chitra P, Saiprasad G, Manikandan R, Sudhandiran G. Berberine attenuates bleomycin induced pulmonary toxicity and fibrosis via suppressing NF- $\mathrm{BB}$ dependant TGF- $\beta$ activation: a biphasic experimental study. Toxicol Lett. 2013;219(2):178-93. 
23. Gong G-H, An F-M, Wang Y, Bian M, Wang D, Wei C-X. MiR-153 regulates expression of hypoxia-inducible factor- $1 \alpha$ in refractory epilepsy. Oncotarget. 2018;9(9):85428547.

24. Liu X-L, Lu J, Xing J. Stabilization of HIF$1 \alpha$ modulates VEGF and Caspase- 3 in the hippocampus of rats following transient global ischemia induced by asphyxial cardiac arrest. Life Sci. 2016;151:243-249.

25. Mao L, Chen Q, Gong K, Xu X, Xie Y, Zhang W, et al. Berberine decelerates glucose metabolism via suppression of mTOR-dependent HIF-1 $\alpha$ protein synthesis in colon cancer cells. Oncol Rep. 2018;39(5):24362442.

26. Huang Y, Doherty JJ, Dingledine R. Altered histone acetylation at glutamate receptor 2 and brain-derived neurotrophic factor genes is an early event triggered by status epilepticus. J Neurosci. 2002;22(19):8422-8.
27. Chiang LW, Grenier JM, Ettwiller L, Jenkins LP, Ficenec D, Martin J, et al. An orchestrated gene expression component of neuronal programmed cell death revealed by cDNA array analysis. Proc Natl Acad Sci U S A. 2001;98(5):2814-9.

28. Ballas N, Battaglioli E, Atouf F, Andres ME, Chenoweth J, Anderson ME, et al. Regulation of neuronal traits by a novel transcriptional complex. Neuron. 2001;31(3):353-65.

29. Jessberger S, Nakashima K, Clemenson GD, Mejia E, Mathews E, Ure K, et al. Epigenetic modulation of seizure-induced neurogenesis and cognitive decline. J Neurosci. 2007;27(22):5967-75.

30. Shen J-d, Ma L-g, Hu C-y, Pei Y-y, Jin S-1, Fang $X-y$, et al. Berberine up-regulates the BDNF expression in hippocampus and attenuates corticosterone-induced depressivelike behavior in mice. Neurosci Lett. 2016;614:77-82. 